\title{
Space Geodesy Application for the Natural Hazards Monitoring of the Russian Far Eastern Territory
}

\author{
Suriya Tatevian \\ Institute of Astronomy, Russian Academy of Sciences, Moscow 119017, Russia
}

\begin{abstract}
This is a brief overview of the surveys aimed at the studies of the Russian Eastern Asian area, which has a complicate geological structure and tectonics, because of convergence of three tectonic plates (Eurasian-EUR, North American—NAM and Pacific_PAC). An existence of several independent microplates (Okhotsk-OKH, Amur-AMU and Bering-BER) is assumed to be there. A multinational Circum-Pacific geodetic network for monitoring the tectonic movements in the region is critical. From this point of view, new developed Russian fundamental geodetic network will be very effective.
\end{abstract}

Key words: GNSS (Global Navigation Satellite Systems) measurements, tectonic movements, Kamchatka-Aleutian-Alaska ark geodetic monitoring.

\section{Introduction}

Scientists and program leaders from the Russian and USA. governments agencies met in Moscow (July 17-19, 2012) at the United States-Russia Geohazards Workshop to identify bilateral cooperative actions for disaster risk reduction, focusing on extreme geophysical events. The workshop activity is under the Bilateral Presidential Commission Science and Technology Working Group as agreed upon at the bilateral meeting held on December 15, 2011 in Washington, DC. The focus of the workshop was on the geodynamical active Russia-USA border region that includes the Kamchatka Peninsula, Aleutian Islands, and Alaska — an area subject to some of the largest earthquakes, volcanic eruptions, and tsunamis. In his very detailed lecture "Earthquake Hazards and Disasters in the Kamchatka-Alaska region”, professor E. Gordeev from the Institute of Volcanology and Seismology RAS (Russian Academy of Sciences) argued an importance of the joined geodynamical studies of the Alaska-Aleutian-Kamchatka ark with different modern techniques. He shows that the

Corresponding author: Suriya Tatevian, professor, research fields: space, geodesy, geodynamics. E-mail: statev@inasan.ru. western Bering Sea margin is tsunamigenic and disastrous events should be expected in this region in the near future. In his opinion, the topical questions in Kamchatka-Aleutian region (Fig. 1) are:

(1) Does Okhotia and Beringia exist?

(2) Where are the plate boundaries?

(3) The nature of Aleutian-Kamchatka interaction: does Aleutians collide with Kamchatka and where is the collision boundary?

The participants of the workshop agreed that:

- The Kamchatka-Aleutian-Alaska region has to be a component of the multinational Circum-Pacific geodetic monitoring network that could operate in real time;

- Comprehensive hazard assessment of great earthquakes and tsunamis in the region should be based on a multi-disciplinary approach to link geodynamics, seismology and paleoseismology, tsunami and paleotsunami research with geodesy, remote sensing and some other geophysical and geological disciplines;

- There is an urgent need for credible models and forecasts of future great subduction zone earthquakes and tsunamis in the region; 


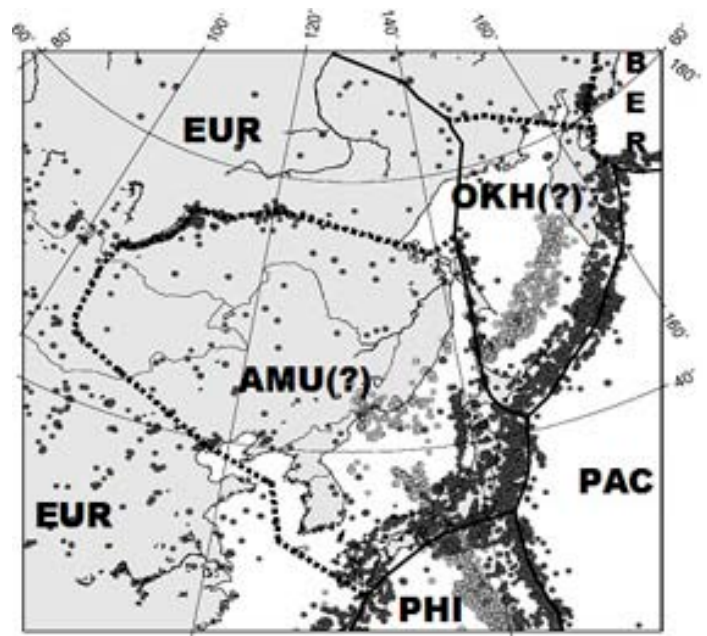

Fig. 1 Plate boundaries in the Alaska-Aleutian-Kamchatka ark’s region.

- Given the peril of major volcanic eruptions on air traffic, and earthquakes associated tsunamis—such a circum Pacific network would be critical.

\section{Application of Space Geodetic Techniques for the Earth's Crust Motions Studies}

\subsection{GPS Measurements Campaigns in the Region}

During the last 17 years, the GPS (global positioning system) techniques have been used for studying the recent crustal velocities in the Russian Eastern Asian area, where three tectonic plates (Eurasian-EUR, North American-NAM and Pacific-PAC) contiguous to each other and an existence of several independent microplates are assumed to take place there (Fig. 2).

In 2008-2009, more than 10 permanent GPS/GLONASS (Global Navigation Satellite System) sites [1] have started measurements in the South of the Russian Far East under the Scientific Federal program "Recent geodynamics, active geologic structures and natural hazards of Russian Far East”. And an array of permanent and survey-mode GPS sites was installed over almost all Kuril Islands under collaboration of the Russian Academy of Sciences and Lamont-Doherty Earth Observatory (USA). Five local research groups are involved in processing of the GNSS data [2]. Subject of investigations is an estimation

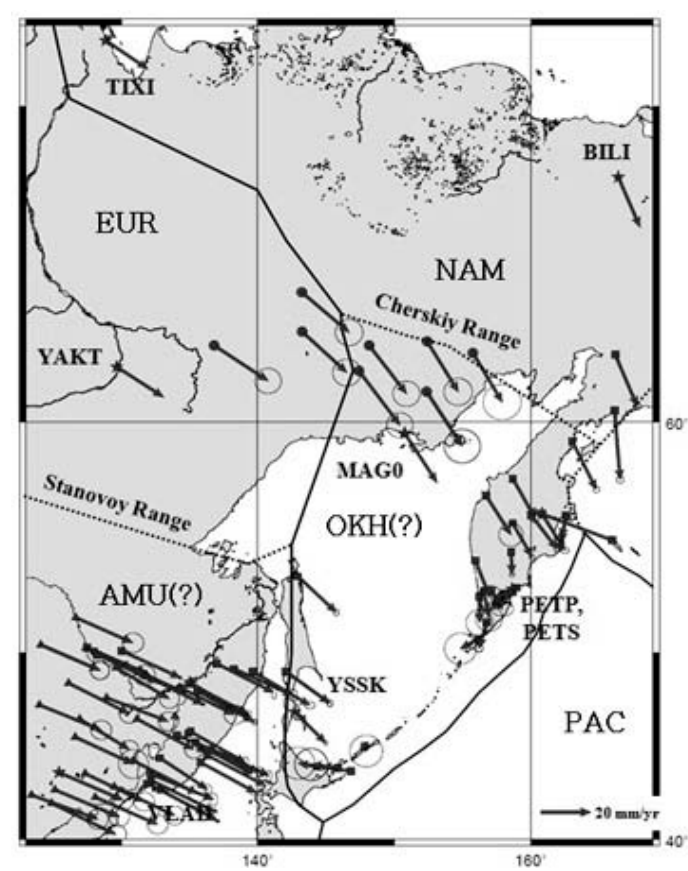

Fig. 2 Sites velocities as estimated by GPS observations.

of daily positions and velocities of geodynamic network sites and their variance-covariance matrix. All obtained by different scientific groups GPS velocities were transformed into the International Terrestrial Reference Frame (ITRF2008) [3, 4] through the six-parameter Helmert transformation (three translations and three rotations) by using GPS velocities of a set of common sites of the ITRF network, which were included into each regional GPS solution.

\subsection{Russian Fundamental Geodetic Network}

China, Japan, Canada, and the US have fairly advanced reference networks in this region. And an establishment of the fundamental geodetic network, integrated with ITRF, is carried out in Russia [5, 6]. This network provides a representative covering of the largest stable areas (the Siberian and the East European) of the Eurasian plate and will be used as a reference frame for geodynamic studies of the active plate boundary between the PA (Pacific), NA (North American) and EU (Eurasian) plates. GLONASS is considered as a key technology for the precise positioning and for establishment of the new 
Terrestrial Reference Frame in Russia. The comparative analyses show that the availability of the GLONASS is better than GPS availability at the latitudes more than $45^{\circ}$. In the near-polar regions, an availability of the GLONASS is the highest. But in the near equatorial zones, an availability of navigation with GLONASS becomes worse than with GPS. A joint use of these two systems for the navigation in the urban and mountain broken areas with a great mask angle is of special interest for users.

To compare the positioning accuracy estimated with the use of GLONASS (full constellation) and GPS data, obtained at the 15 new sites of the Russian fundamental geodetic network were analyzed at the Institute of Astronomy (Moscow) [7]. The stations are equally distributed and equipped with different types of dual receivers (Fig. 3).

Daily measurements with $30 \mathrm{~s}$ recording of the data from every station have been processed with the use of GIPSY-OASIS II (Linux version 6.1.2), developed at the JPL (Jet Propulsion Laboratory) NASA [8, 9]. The strategy of the PPP (precise point positioning) [7] has been applied for the analyses of GPS and GLONASS measurements separately, with the use of utility gd2p.pl (GNSS data to position) of the software. Outcome of the performed computations shows that rms (mean square residuals) of the new sites of the Russian geodetic network were determined with the precision (rms) 1-10 $\mathrm{mm}$ with the use of measurements during a half-year time period. The differences between coordinates of the new Russian sites, estimated by only GPS or GLONASS measurements, are in the limits of 2-10 mm.

\section{Results and Discussion}

As a result of the GPS local measurements for studies of the recent crustal velocities in the Russian Eastern Asian area, where three tectonic plates (Eurasian-EUR, North American-NAM and Pacific-PAC) are contiguous to each other, the following conclusions have been made:

- Recent crustal velocities of the northern part of Russian Far East are defined by the NAM-plate rigid rotation (western part) and interaction with PAC-plate (eastern part);

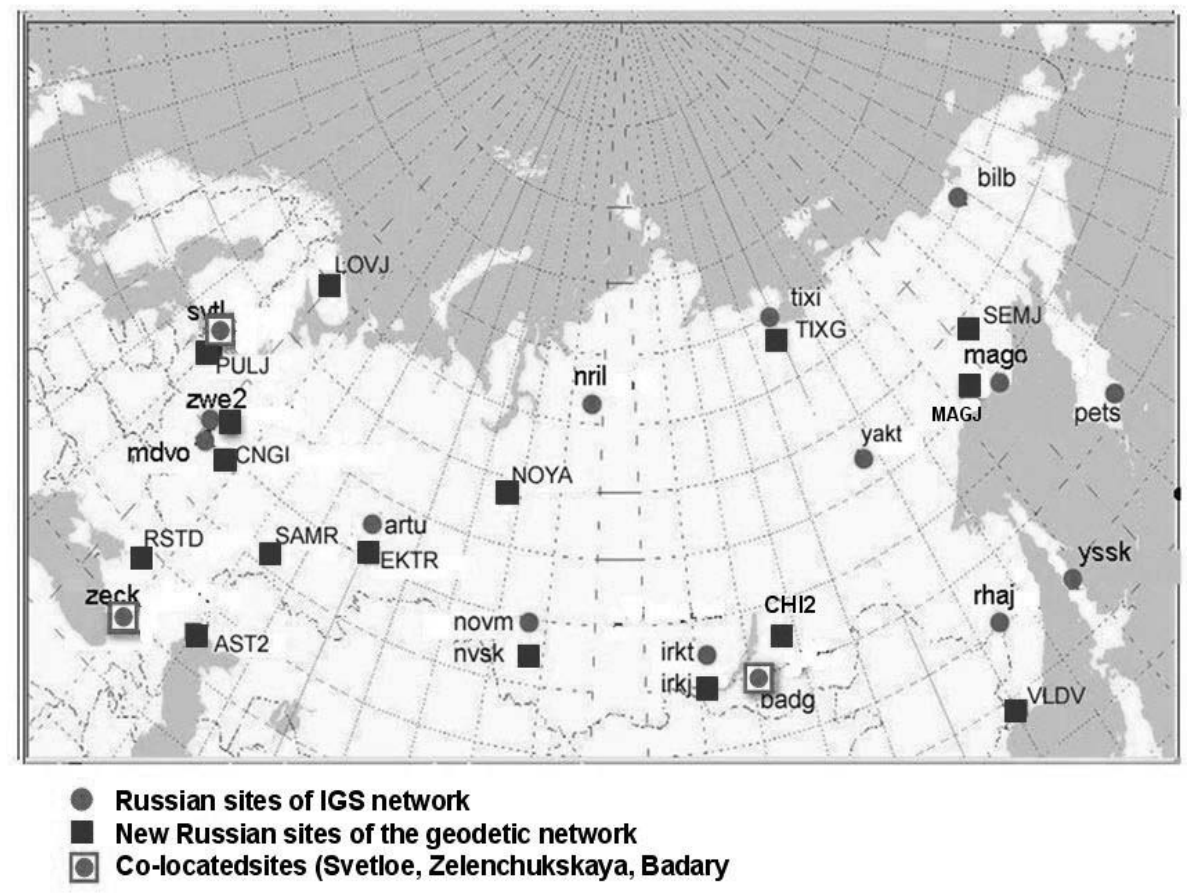


Fig. 3 Russian GPS/GLONASS network (2013).

- GPS velocity field near the CSAF does not reflect any noticeable recent geodynamic activity of the CSAF as a whole, but local scale activity connected with individual tectonic blocks could not be excluded;

- The GPS velocity field of Sakhalin Island demonstrates sub-latitudinal contraction and stress accumulation. The EUR-velocities are increasing from the north $(4 \mathrm{~mm} / \mathrm{yr})$ to the south $(8 \mathrm{~mm} / \mathrm{yr})$ of the island. A velocity boundary between continental part and Sakhalin Island was estimated by GPS data;

- GPS velocities of the south-eastern part of the Russian Far East referenced to EUR are small enough (less than $5 \mathrm{~mm} / \mathrm{yr}$, a median value around $1 \mathrm{~mm} / \mathrm{yr}$ ). A domination of the east component is shown. They do not correspond perfectly to well-known AMU—micro plate rigid rotation model.

Recent geodynamics of the central part of the Russian Far East (region near the Stanovoy Range) has to be investigated by GPS methods in details during the nearest future.

\section{Conclusions}

The geodynamical active region which includes Kamchatka Peninsula, Aleutian Islands, and Alaska requires attention to disaster risk reduction by all countries of the North Pacific. The Russian fundamental geodetic network is considered as a component of the multinational Circum-Pacific geodetic monitoring network that could operate in real time.

A multi-disciplinary approach has to be used to combine geodynamics, seismology and tsunami studies with geodesy, remote sensing and some other geophysical disciplines.

\section{Acknowledgments}

The author is very thankful to professor E. Gordeev, Dr. N. Shestakov, and professor G. Demyanov for their kind permissions to show their results and figures in this paper.

\section{References}

[1] Kuzin, S., Revnivykh, S., and Tatevian, S. 2007.“Glonass as a Key Element of the Russian Positioning Service.” Advances in Space Research 39 (10): 1531-8.

[2] Shestakov, N. V., Gerasimenko, M. D., Takahashi, H., Kasaha, M., Bormotov, V. A., Bykov, V. G., and Kolomiets, A. G. 2011. "Present Tectonics of the Southeast of Russia as Seen from GPS Observations.” GJI Geodynamics and Tectonics 184: 529-40. doi:10.1111/j.1365-246X.2010.04871.x.

[3] Altamimi, Z., Collilieux, X., and Legrand, J. 2007. "ITRF2005, a New Release of the International Terrestrial Reference Frame Based on Time Series of Station Positions and Earth Orientation Parameters.” J. Geophys. Res. 112 (B9), art. B09401.

[4] Altamimi, Z., Callilieux, X., and Metivier, L. 2011. "ITRF 2008: An Improved Solution of the International Terrestrial Reference Frame.” J.Geod v. 85: 457-73. doi:10.1007/s00190-011-0444-4.

[5] Demyanov, G. V., and Tatevian, S. K. 2000. "Integrated Geodynamical Network in Russia. (Scientific Objectives and Realization).” Phys.Chem.Earth (A) 25 (12): 819-22.

[6] Tatevyan, S., and Kuzin, S. 2010. "On the Combined Use of GPS/GLONASS Techniques for the Development of the Russian Geodetic Reference Network.” Advances in Geosciences, edited by Kenji, S., WSPC. Vol. 26, 23-32.

[7] Tatevian, S., and Kuzin, S. 2013. "On the Use of GLONASS for Precise Positioning.” Journal of Remote Sensing Technology 1 (2): 31-5.

[8] Webb, F., and Zumberge, J., eds. 1995. An Introduction to GIPSY-OASIS II. Report JPLM D-11088, Jet Propulsion Laboratory, Pasadena.

[9] Zumberge, J. F., Heflin, M. B., Jefferson, D. C., Watkins, M. M., and Webb, F. H. 1997. "Precise Point Positioning for the Efficient and Robust Analysis of GPS Data from Large Networks.” J.Geophys.Res 102 (B3): 5005-16. 